\title{
Enterococci in river Ganga surface waters: Propensity of species distribution, dissemination of antimicrobial-resistance and virulence-markers among species along landscape Pushpa Lata1, Siya Ram¹, Madhoolika Agrawal² and Rishi Shanker*1
}

Address: ${ }^{1}$ Environmental Microbiology Division, Indian Institute Toxicology Research (C.S. I.R.), Post Box 80, Mahatma Gandhi Marg, Lucknow226001, U.P, India and ²Department of Botany, Banaras Hindu University, Varanasi-221005, U.P, India

Email: Pushpa Lata - pushpalata0@gmail.com; Siya Ram - siyaram1@rediffmail.com; Madhoolika Agrawal - madhoo58@yahoo.com; Rishi Shanker* - rishishanker@gmail.com

* Corresponding author

Published: 18 July 2009

BMC Microbiology 2009, 9:140 doi:10.1/86/147I-2180-9-140
Received: 29 December 2008

Accepted: 18 July 2009

This article is available from: http://www.biomedcentral.com//47/-2/80/9//40

(c) 2009 Lata et al; licensee BioMed Central Ltd.

This is an Open Access article distributed under the terms of the Creative Commons Attribution License (http://creativecommons.org/licenses/by/2.0), which permits unrestricted use, distribution, and reproduction in any medium, provided the original work is properly cited.

\begin{abstract}
Background: Surface waters quality has declined in developing countries due to rapid industrialization and population growth. The microbiological quality of river Ganga, a life-sustaining surface water resource for large population of northern India, is adversely affected by several point and non-point sources of pollution. Further, untreated surface waters are consumed for drinking and various household tasks in India making the public vulnerable to water-borne diseases and outbreaks. Enterococci, the 'indicator' of water quality, correlates best with the incidence of gastrointestinal diseases as well as prevalence of other pathogenic microorganisms. Therefore, this study aims to determine the distribution of species diversity, dissemination of antimicrobialresistance and virulence-markers in enterococci with respect to rural-urban landscape along river Ganga in northern India.
\end{abstract}

Results: Enterococci density $\left(\chi^{2}: 1900, d f: I ; p<0.0001\right)$ increased from up-to-down gradient sites in the landscape. Species diversity exhibit significant $\left(\chi^{2}: 100.4, \mathrm{df}: 20 ; p<0.000 \mathrm{I}\right)$ and progressive distribution of $E$. faecalis, $E$. faecium, $E$. durans and $E$. hirae down the gradient. Statistically discernible ( $p$ : $0.0156-<0.0001$ ) background pool of resistance and virulence was observed among different Enterococcus spp. recovered from five sites in the up-to-down gradient landscape. A significant correlation was observed in the distribution of multiple-antimicrobial-resistance (viz., erythromycin-rifampicin-gentamicin-methicillin and vancomycin-gentamicin-streptomycin; $r_{s}$ : 0.9747; p: 0.0083) and multiple-virulence-markers (viz., gelE ${ }^{+} e s p^{+} ; r_{s}: 0.9747 ; p: 0.0083$; gelE ${ }^{+} \mathrm{efaA}^{+}$; $\left.r_{s}: 0.8944 ; p: 0.0417\right)$ among different Enterococcus spp.

Conclusion: Our observations show prevalence of multiple-antimicrobial-resistance as well as multiple-virulence traits among different Enterococcus spp. The observed high background pool of resistance and virulence in enterococci in river waters of populous countries has the potential to disseminate more alarming antimicrobial-resistant pathogenic bacteria of same or other lineage in the environment. Therefore, the presence of elevated levels of virulent enterococci with emerging vancomycin resistance in surface waters poses serious health risk in developing countries like India. 


\section{Background}

Enterococci, commensal organisms in gastrointestinal tract of human and animals have emerged as a leading cause of nosocomial infections [1]. Enterococcus faecalis (E. faecalis) and E. faecium are the two major pathogenic species in human, with sporadic infections caused by $E$. durans, E. hirae and other enterococci [2]. The presence of enterococci as an indicator of fecal contamination has been used in management of recreational water quality standards as it correlates best with the incidence of swimming-related illnesses $[3,4]$. Various virulence traits such as gelatinase ( $g e l E)$, enterococcal surface protein (esp), collagen binding protein (ace) and endocarditis-associated antigen ( $e f a A$ ) have been considered as possible factors to play an important role in making enterococci a potential pathogen [5-7]. The enterococcal infections caused due to the potential virulence factors are difficult to treat because of the high level of intrinsic antimicrobial-resistance [8]. Several independent studies have reported the spread of antimicrobial-resistance and virulence-markers in clinical settings [2,9-13]. However, very little is known about the distribution of antimicrobial-resistance and virulencemarkers among different species of enterococci from surface waters $[14,15]$.

The surface waters in populous countries have become reservoirs of antimicrobial-resistant pathogenic microbes due to indiscriminate use of antimicrobials in human and veterinary medicine and addition of fecal contamination through point as well as non-point sources, storm drain infrastructure and malfunctioning septic trenches [16]. The propensity of species dissemination and prevalence of background level of antimicrobial-resistance is influenced by a variety of biotic and abiotic factors including geographical area and demography [17]. Recently, the presence of STEC (Shiga toxin producing E. coli) and ETEC (Enterotoxigenic E. coli) specific virulence genes and E. coli resistant to multiple antimicrobials has been reported from selected locations of river Ganga [18]. However, there is paucity of information on the concentration of enterococci and distribution of associated antimicrobial- resistance and virulence-markers in river Ganga. The river Ganga is a major river of Indian subcontinent traversing $2510 \mathrm{~km}$ across the country. The river and its tributaries provide $40 \%$ of water requirement of the country for various purposes including irrigation, daily use and drinking [19]. About 2460 million liters per day (mLd) of domestic sewage waste and $4570 \mathrm{mLd}$ of raw sewage (from 223 cities and towns) directly finds its way into the river through its tributaries [20]. Further, other non-point sources include wastes from agriculture, health sector, practices of holy-dip and crematory processes along the banks.

The goal of current study was to contextualize the dissemination of species diversity, antimicrobial-resistance and virulence-markers in enterococci with respect to ruralurban landscape along river Ganga in northern India.

\section{Results and discussion \\ Concentration of enterococci}

Median concentrations of fecal streptococci or enterococci increased gradually and significantly $\left(\chi^{2}: 1900\right.$, df: $1 ; p<$ $0.0001)$ in the river Ganga surface waters from up-todown-gradient sites in the landscape (Table 1). The most downstream site was 53 and > 25000-fold more polluted than the most upstream site, using MPN test and membrane filtration method, respectively (Table 1). These observations concur with recent reports that determined the presence of fecal indicators in surface water gradients $[18,21,22]$. In the present study, we observed an increasing trend of enterococci concentration in the range of 2.3$4.4 \times 10^{1} \mathrm{CFU} / 100 \mathrm{~mL}, 1.0-1.2 \times 10^{3} \mathrm{CFU} / 100 \mathrm{~mL}, 6.7-$ $7.7 \times 10^{4} \mathrm{CFU} / 100 \mathrm{~mL}, 4.4-5.1 \times 10^{4} \mathrm{CFU} / 100 \mathrm{~mL}$ and $7.8-8.7 \times 10^{5} \mathrm{CFU} / 100 \mathrm{~mL}$ at sites $1,2,3,4$ and 5 respectively (Figure 1). Internationally, the single-sample advisory limit of enterococci for fresh water is $61 \mathrm{CFU} / 100 \mathrm{~mL}$ and the 5-day geometric mean should not exceed $33 \mathrm{CFU} /$ $100 \mathrm{~mL}$; while Indian standards do not delineate the limit for enterococci in terms of CFU/100 mL [3,19].

Table I: Quantitative enumeration and density estimation of enterococci in surface water samples $(n=15)$ collected from sites $(n=5)$ located on river Ganga (Kanpur city) in up-to-down-gradient fashion

\begin{tabular}{|c|c|c|c|}
\hline Sampling Site & $\begin{array}{l}\text { CFU/I00 ml water } \\
\text { [Median (Range)] }\end{array}$ & MPN index/l00 ml water (Lower $95 \% \mathrm{Cl}-$ Upper $95 \% \mathrm{Cl}$ ) & $p$-Value ${ }^{b}$ \\
\hline Site I & $32(23-44)$ & $30(10-110)$ & \\
\hline Site 2 & $1130(1034-1211)$ & $220(100-580)$ & \\
\hline Site 3 & $73000(67532-76848)$ & $350(160-820)$ & $<0.0001 * * *$ \\
\hline Site 4 & $48000(43978-51078)$ & $300(100-1300)$ & \\
\hline Site 5 & $820000(78284|-87| 978)$ & $1600(600-5300)$ & \\
\hline Controlc & ND & ND & \\
\hline
\end{tabular}

aLower $95 \% \mathrm{Cl}$ - Upper $95 \% \mathrm{Cl}$ are adopted from Table $9221 . \mathrm{IV}$, Section $922 \mathrm{IC}$. Estimation of Bacterial density, APHA (1998). bp-Value was calculated using chi square test for trend, $\chi^{2}=1900 ; \mathrm{df}=1$. cSterile Milli $\mathrm{Q}$ water used as control. ***Statistically significant at alpha $<0.05$. Abbreviations: ND, Not Detected. 


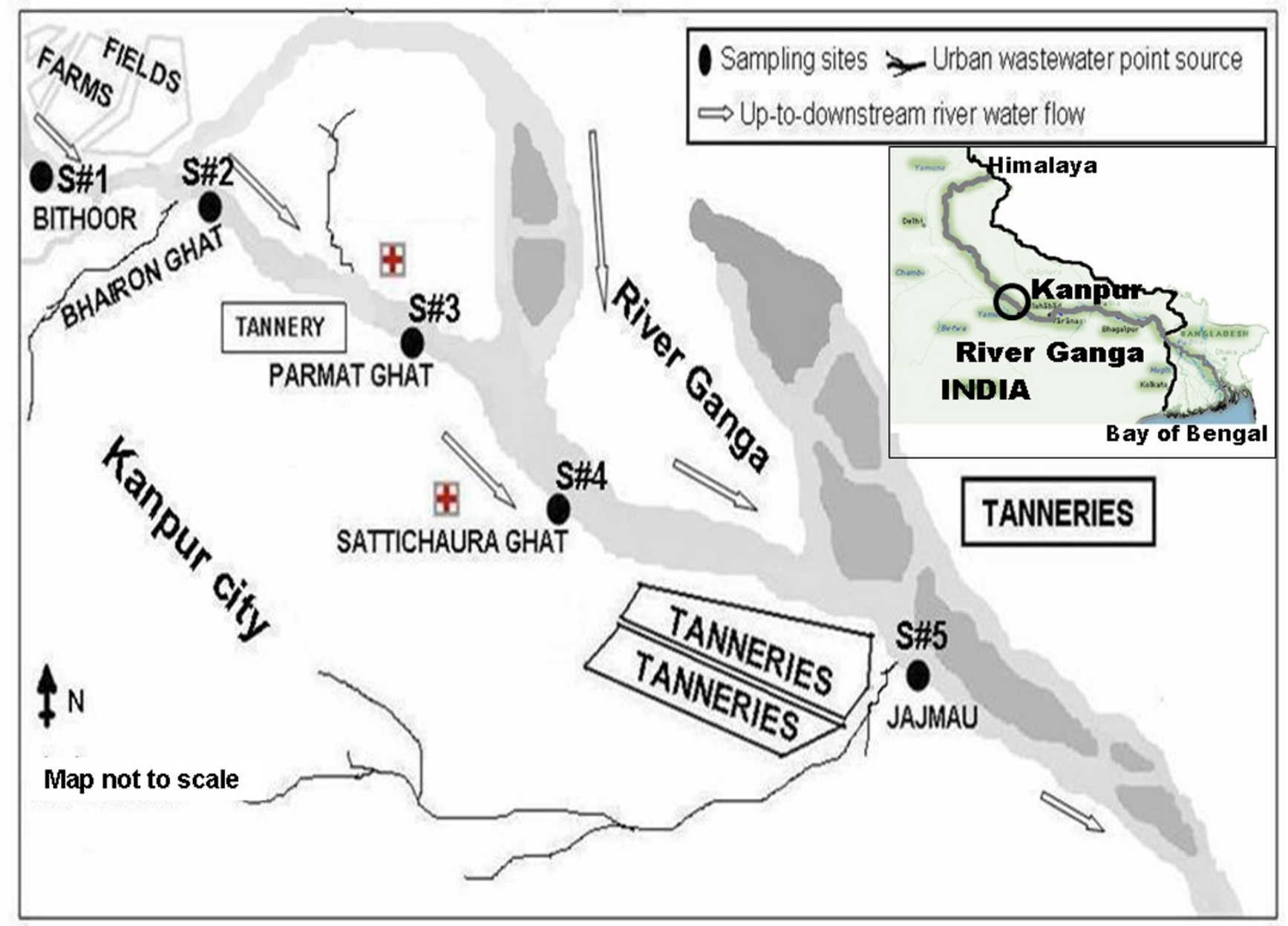

Figure I

Map of study area/sampling sites in the landscape. Inset view simulates the complete $2510 \mathrm{~km}$ stretch of river Ganga from Himalaya to Bay of Bengal. Abbreviations: S\#I, site I: Bithoor (most upstream site); S\#2, site 2: Bhairon ghat; S\#3, site 3: Parmat ghat; S\#4, site 4: sattichaura ghat or nana-rao ghat; S\#5, site 5: jajmau (most downstream site). Arrows indicate the direction of surface water flow in the up-to-down-gradient fashion in the landscape. Topographic data based upon Survey of India map (adopted from http://www.ttkmaps.com).

Table 2: Frequency of distribution of Enterococcus spp. diversity among sites $(n=5)$

\begin{tabular}{|c|c|c|c|c|c|c|c|}
\hline \multirow[t]{2}{*}{ Sampling Site } & \multicolumn{6}{|c|}{ No. of isolates (\%) } & \multirow[t]{2}{*}{$p$-Value } \\
\hline & E. faecalis & E. faecium & E. durans & E. hirae & other Enterococcus spp. & Total enterococci per site & \\
\hline site I & $5(5.95)$ & I (I.19) & 0 & 0 & 0 & $6(7.14)$ & \\
\hline site 2 & $9(10.71)$ & $4(4.76)$ & $4(4.76)$ & 0 & 0 & $17(20.24)$ & \\
\hline site 3 & $12(14.29)$ & $6(7.14)$ & 0 & I (I.19) & 0 & $19(22.62)$ & \\
\hline site 4 & $12(14.29)$ & $3(3.57)$ & $3(3.57)$ & 0 & 0 & $18(21.43)$ & $<0.000 I^{* * * *}$ \\
\hline site 5 & $16(19.05)$ & $6(7.14)$ & 0 & I (I.19) & I (I.19) & $24(28.57)$ & \\
\hline Enterococcus spp. distribution & $54(64.29)$ & $20(23.8 I)$ & $7(8.33)$ & $2(2.38)$ & I (I.19) & $84(100)$ & \\
\hline
\end{tabular}

ap-Value was calculated using chi square test, $\chi^{2}=100.4 ; \mathrm{df}=20$. *** Statistically significant at alpha $<0.05$. 


\section{Enterococcus spp. isolated from river Ganga waters} A significant $\left(\chi^{2}: 100.4, \mathrm{df}: 20 ; p<0.0001\right)$ heterogeneity and diversity was observed in Enterococcus spp. recovered from river Ganga surface water samples collected from five different sites (Table 2). The spatial heterogeneity of Enterococcus spp. varied widely along the landscape, depending upon exposure to various environmental and anthropogenic factors. In general, the enterococcal spatial heterogeneity seems to be introduced either via point sources (urban sewage, clinical and industrial discharge) or nonpoint sources (agricultural runoff and storm-water route).E. faecalis (64\%) was found to be the most prevalent species followed by E. faecium (24\%) throughout the landscape. A gamut of factors appears to complement the increase of E. faecalis and E. faecium coexistence towards the down-gradient sites in the similar environmental niche. The coexistence of these two genotypes in one niche may be due to their differential affinity and efficiency of resource utilization complementing similar phenomenon reported elsewhere for Vibrio cholerae serogroups; O139 Bengal and O1 E1 Tor [23]. In the same study, the enhanced affinity of $V$. cholerae O1 E1 Tor to colonize copepods was observed to be a contributory factor for its dominance in cholera epidemic. Likewise E. faecalis, the most prevalent species observed in this study has been implicated in $c a$. $67 \%$ and $90 \%$ of enterococcal infection cases associated with multiple-antimicrobialresistance in different clinical studies conducted in India and USA respectively $[12,24]$. E. durans and E. hirae were not evenly distributed throughout the landscape. The presence of E. hirae (2\%) was observed only at the locations which receive tannery effluents contaminated with heavy metals. The prevalence of $E$. durans (8\%) appears to be affected by urban wastewater point-source contamination. The "other Enterococcus spp." was present at site 5 only. Moreover, it appears that the environmental factors account for the spatial variation of Enterococcus spp. in the landscape.

\section{Antimicrobial-resistance}

This study investigated the background pool of antimicrobial-resistance (BPAR) in the landscape. High frequency of multiple-antimicrobial-resistance (MAR) was recorded among enterococci tested. The number (median) of antimicrobials against which resistance was observed in each Enterococcus isolate increased significantly ( $p$ 0.0156, $0.0001,<0.0001,0.0001,<0.0001)$ towards downstream in the landscape (Table 3). The prevalence of resistance to a minimum of five antimicrobials per isolate reflects high BPAR in the up-to-down gradient landscape. This high value of BPAR at most upstream site could be attributed to the agriculture farms, intensive livestock and swine farming in the locality. Although there is no data available from India, the prevalence of VRE on site 1 may be due to the use of antimicrobials in the animal feed and cattle or swine manure application in the fields, reported to be important contributing factors elsewhere $[25,26]$. The urban sewage waste contributed to the maintenance of resistance pool at site 2 . The elevated level of resistance at site 3 was a likely contribution from hospital, tannery, and sewage discharging point sources leading to microbial, chemical as well as antimicrobial contamination. The lower concentration of enterococci and reduced resistance pool at site 4 , as compared to site 3 , is possibly due to confluence of two watersheds just upstream of site 4 resulting in dilution of the pre-existing microbial biogeography and associated traits. Site 5, the most downstream sampling station in the landscape presents the worst scenario of microbial contamination and reflects the best spatial correlation among enterococci concentration, species diversity, antimicrobial-resistance and virulence-markers' dissemination.

Table 3: Antimicrobial-resistance and virulence-markers investigated in each Enterococcus isolate on sites located in the up-to-downgradient landscape

\begin{tabular}{|c|c|c|c|}
\hline Sampling site & $\begin{array}{c}\text { No. of samples analyzed for antimicrobial susceptibility or } \\
\text { virulence-marker/s (\%) }\end{array}$ & $\begin{array}{l}\text { Antimicrobial-resistance (AR) and Virulence-markers (VM) } \\
\text { characterized per isolate } \\
{[\text { Median (Range) }]^{\mathrm{a}}}\end{array}$ & $p$-Value ${ }^{b}$ \\
\hline \multirow[t]{2}{*}{ site I } & $6(7.14)$ & AR: $5(3-6)$ & $0.0156 *$ \\
\hline & & VM: $2(I-3)$ & $0.0156 *$ \\
\hline \multirow[t]{2}{*}{ site 2} & 17 (20.24) & AR: $5(4-5)$ & $0.0001 *$ \\
\hline & & VM: $2(I-2)$ & $0.0002 *$ \\
\hline \multirow[t]{2}{*}{ site 3} & $19(22.62)$ & AR: $7(5-7)$ & $<0.0001 *$ \\
\hline & & VM: I (I - 4) & $<0.0001 *$ \\
\hline \multirow[t]{2}{*}{ site 4} & I8 (2I.43) & AR: $5(5-6)$ & $0.0001 *$ \\
\hline & & VM: $2(I-2)$ & $<0.0001 *$ \\
\hline \multirow[t]{2}{*}{ site 5} & $24(28.57)$ & AR: $5(5-6)$ & $<0.0001 *$ \\
\hline & & VM: $2(2-3)$ & $<0.0001 *$ \\
\hline
\end{tabular}

aMedian and range are reported to match more consistently with the nonparametric statistical tests performed. ap-Value was calculated using Wilcoxon rank sum test. *Statistically significant at alpha $=0.05$. 
Statistically detectable MAR was recorded among Enterococcus spp. isolates [Figure 2 and Additional file 1]. E. faecium resistant to $\beta$-lactam class of antimicrobials including methicillin was recorded to be higher in this landscape. A large scale dissemination of aminoglycoside resistance was observed along the landscape gradient; higher percentage of gentamicin resistant enterococci were prevalent at site 3 which reflects its frequent use in human medicine as this site receives wastes from hospital located just upstream. Our observations indicate that streptomycin and gentamicin resistance are distributed extensively in the environmental gene pool. The resistance to erythromycin, a macrolide and rifampicin in association with vancomycin, a glycopeptide was also distributed significantly. Hasman et al. [27], reported a relationship between copper, glycopeptide and macrolide resistance among E. faecium strains isolated from pigs in Denmark during 1997-2003, contemplating persistence of BPAR in that geographic region. A number of studies have reported the phenomenon of sustained BPAR in poultry and local population $[28,29]$.

Though the frequency of VRE is only $21 \%$ in the landscape, its association with other widely disseminated antimicrobials and virulence determinants may lead to evolution of pathogenic VRE and thus reduce the chances for synergistic therapy in case of failure of single antimicrobial [30]. Recently, Lata et al. [31] reported the prevalence of vanA gene (for vancomycin resistance) in surface waters of river Ganga and its tributary and discussed the possible consequences of BPAR, its environmental carriage by plasmid maintenance systems or postsegregational killing (PSK) systems.

\section{Dissemination of virulence-markers}

This study also explored the dynamic and complex facet of landscape and its effects on the dissemination of virulence-markers gelE, ace, efaA and esp among different Enterococcus spp. Statistically discernible distribution of virulence-markers along the up-to-down-gradient landscape was observed (Table 3 ). In addition, the active gelatinase phenotype was observed in $19.05 \%$ E. faecalis isolates [see Additional file 2]. The background level of virulence-markers in the up-to-down gradient landscape exist at least for two virulence-markers predominantly gelE+esp $p^{+}(26.19 \%)$ followed by gelE $e f a A^{+}$(7.14\%). The only exception was site 3 with median value of one which otherwise exhibited the range of one to four virulencemarkers gelE $e f a A^{+}, \quad g e l E^{+} e f a A^{+} e s p^{+}, g e l E^{+} a c e^{+} e f a A^{+}$and $g^{e l E^{+}} a c e^{+} e f a A^{+} e s p^{+}$. The impact of landscape and associated environmental factors seem to affect the dissemination of all four virulence-markers at site 3 which receives contamination from hospital wastes, municipal sewage and tannery effluents. Enterococci isolates from the most polluted downstream site exhibited a range of two to three virulence-markers per isolate; $g e l E^{+} e s p^{+}$and $g e l E^{+} e f a A^{+} e s p^{+}$ combinations were the most prevalent multiple-virulence-traits.

Significantly, the correlation of four virulence-markers was identified either singly or in combination with Enterococcus spp. diversity from river Ganga surface waters (Table 4). Earlier reports on dissemination of virulencemarkers in different enterococci suggest virulence-markers are common trait in the genus Enterococcus[7,32-34]. A recent study has reported the prevalence of gelatinase phenotype of enterococci in agricultural environment and suggested it as reservoir of clinically relevant strains [35]. The pervasiveness of virulence-markers investigated in the current study may be due to the evolution of pathogenic enterococci by natural conjugation in environmental waters that receive potential pathogenic enterococci from various point and non-point sources including urban land use, agriculture, intensive livestock operations, hospital and industrial wastes. The natural processes are too complex to comprehend although the transconjugation experiments conducted elsewhere demonstrated in vitro transfer of additional virulence determinants from clinical strains to starter strains [7]. In the present study, the phenotypic assay for gelatinase activity revealed that certain $E$. faecalis and different Enterococcus spp. isolates contained apparently silent gelE determinant. This observation is supported by an earlier report on presence of silent gelE gene possibly due to inactive gene product or down regulation of gene expression influenced by various environmental factors resulting in lack of phenotypic activity [7]. Further, the activation of silent genes by temporal factors existing in our body, the response of other commensal microbes in the gastrointestinal tract and the persistent presence of large numbers of preexisting commensal enterococci cannot be ignored. Our observation on the loss of gelatinase activity by sub-culturing is also supported by other studies reporting similar phenomena $[7,35]$.

The coselection of resistance to vancomycin, methicillin, gentamicin, streptomycin and ciprofloxacin with gelE virulence-marker was observed in the landscape [see Additional file 2]. An E. faecium isolate was observed with resistance to gentamicin and MAR to vancomycin, erythromycin and rifampicin along with gelE $E^{+} f a A^{+} e s p^{+}$virulence-determinants. The notoriety of E. faecium strains with multiple-antimicrobial-resistance especially VRE in debilitating the disease conditions is well established [10]. The combination of virulence-traits cytolysin-aggregation substance has been demonstrated to be highly coevolved and is efficiently transferred to the sensitive recipients by conjugation [36]. On the other hand a clinical strain of E. faecium having a conjugative plasmid, highly related to pCF10 of E. faecalis, has been shown to confer transferable high-level vancomycin resistance via 

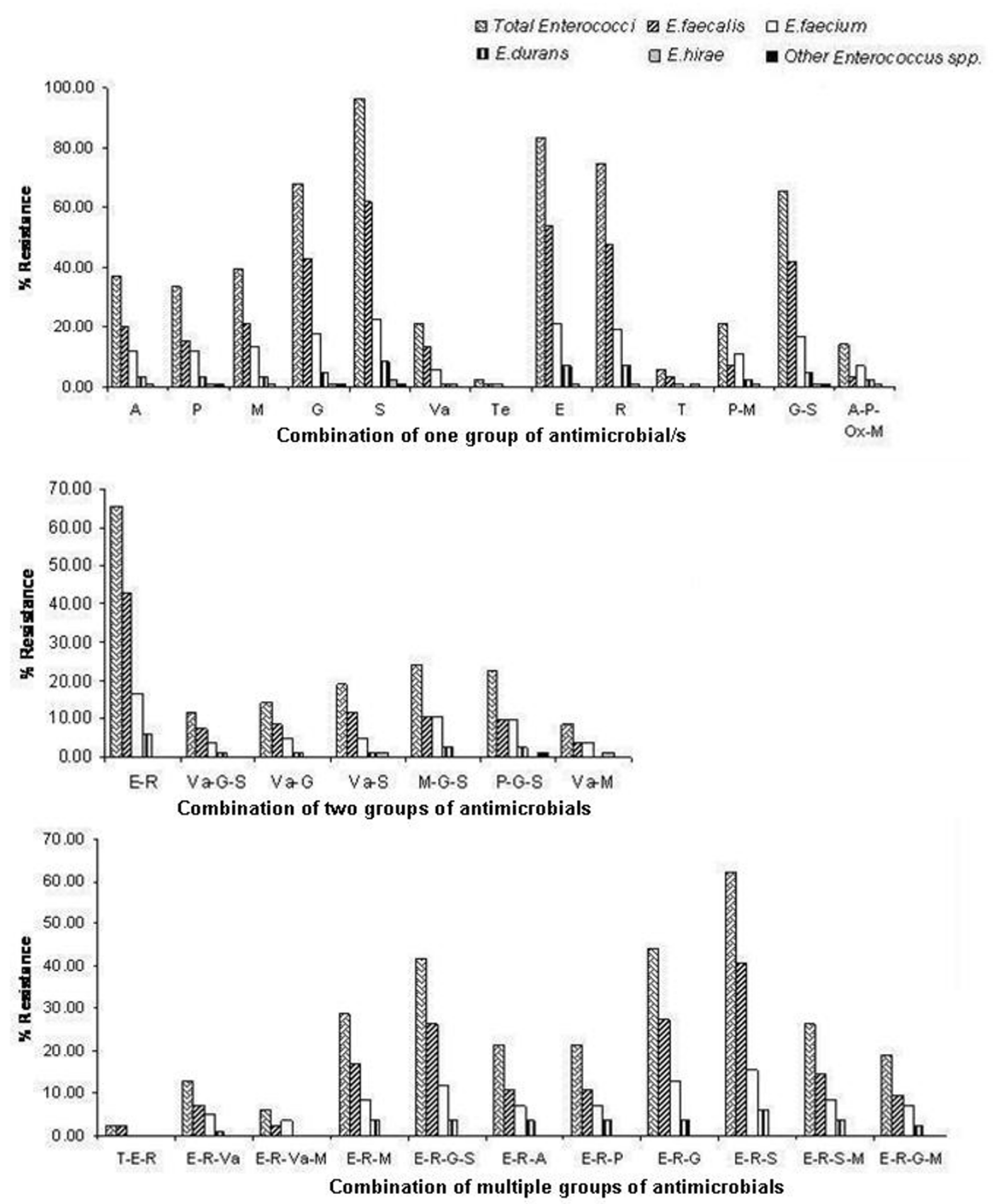

\section{Figure 2}

Distribution of single/multiple-antimicrobial-resistance in different Enterococcus spp. Abbreviations: A, ampicillin; $P$, penicillin G; M, methicillin; G, gentamicin; S, streptomycin (aminoglycoside); Va, vancomycin (glycopeptide); Te, teicoplanin; $E$, erythromycin; R, rifampicin; T, tetracycline; P-M, penicillinG-methicillin; A-P-Ox-M, ampicillin-penicillinG-oxacillin-methicillin ( $\beta$-lactam); E-R, erythromycin-rifampicin (Macrolide-rifamycin); Va-G-S/Va-S/Va-G (glycopeptide-aminoglycoside); M-G-S/P-G-S ( $\beta$-lactam-aminoglycoside); Va-M (glycopeptide- $\beta$-lactam); T-E-R (tetracycline-macrolide-rifamycin); E-R-Va (macrolide-rifamycin-glycopeptide); E-R-Va-M (macrolide-rifamycin-glycopeptide- $\beta$-lactam); E-R-M/E-R-A/E-R-P (macrolide-rifamycin- $\beta$-lactam); E-R-G/E-R-S (macrolide-rifamycin-aminoglycoside); E-R-S-M/E-R-G-M (macrolide-rifamycin-aminoglycoside- $\beta$-lactam). All antimicrobial combinations derived from aforementioned antimicrobial abbreviations. 
conjugation [37]. These evidences indicate the possible transfer of linked virulence-traits and antimicrobial-resistance viz., vancomycin resistance in the landscape. Further the persistence of VRE in the environment even in the absence of antimicrobial selection pressure has been attributed to multiple types of PSK systems or Toxin-Antitoxin (TA) systems $[28,38,39]$. Though till date no role has been assigned to TA systems with respect to linked traits like multiple-antimicrobial-resistance and multiplevirulence-markers in VRE; it is possible that such systems might be playing pivotal role in persistence and dissemination of perilous antimicrobial-resistant pathogenic enterococci.

\section{Limitations}

Pitfalls and associated plausible explanations of this study concern (i) conventional culture based methodology opted for isolation of environmental strains; influenced by the dominance of culturable bacteria and does not consider viable but non-culturable (VBNC) entities which carry potential pathogenic and MAR traits to impart serious infections. The molecular metagenome based approach has been taken into account for our ongoing studies to overcome the limitation. (ii) Limiting landscape to a small geographic region due to financial constrains; consequently the most upstream location in the landscape does not hold the merit of pristine location to be considered for absolute estimation of background level or pool of resistance or virulence-determinants, only relative estimation of background level of resistance is the feasible option. More collaboration between the national and international labs is needed for the purpose. (iii) Lack of exact data on usage pattern of antimicrobials in human and veterinary medicine which further limits the study as the quantitative nature of cause-effect relationship remains partially explored. Strict rule codes needed to be set and maintained by the regulatory agency for local counterparts to keep the track record of supply as well as nature and mode of consumption. However, the intricacies in retrieving specific antimicrobial usage data based on individual consumption continue to be a global challenge for environmental health researchers in the absence of national and or state regulations that require consumers to report their consumption to the local authority as earlier mentioned by Sapkota et al [22].

\section{Conclusion}

In the present study, the spread of potential pathogenic enterococci appears to be the manifestation of complex network of ecological processes and associated factors in the landscape of river Ganga. Enterococci recognized as hardy and rogue microbe may cause very serious infections with limited options of treatment. Surface waters with emerging VRE and background pool of multipleantimicrobial-resistant and multi-virulent enterococci can contribute to the dissemination of resistance and virulence-determinants in the diverse Enterococcus spp. and other bacteria. Therefore, the presence of antimicrobialresistant pathogenic enterococci in surface waters of populous nations demand improved surveillance for risk assessment and pre-emptive strategies for protection of public health.

\section{Methods \\ Study site}

The study was performed along $30 \mathrm{~km}$ landscape in and around Kanpur city (geographic coordinates: $26.4670^{\circ}$ North and $80.3500^{\circ}$ east, area: $1600 \mathrm{~km}^{2}$, estimated population: 4,864,674) located on the banks of river Ganga in up-to-down-gradient fashion (Figure 1). The most upstream Site 1 is Bithoor, a rural area with agricultural farms located $20 \mathrm{~km}$ upstream of the city. Site 2 is Bhairon ghat, it receives municipal waste from the locality. Site 3 is Parmat ghat, receives contamination through urban sewage, hospital and one tannery located upstream to it. Site 4 is Sattichaura ghat and two watersheds of river Ganga

Table 4: Correlation observed for the prevalence of single/multiple-virulence-markers along with Enterococcus spp. diversity in the landscape.

\begin{tabular}{|c|c|c|c|c|c|c|c|c|c|}
\hline \multirow[b]{2}{*}{ S. No } & \multirow[b]{2}{*}{$\begin{array}{l}\text { Combination of } \\
\text { virulence-marker/s }\end{array}$} & \multicolumn{6}{|c|}{ No. of isolates (\%) } & \multirow[b]{2}{*}{$\begin{array}{l}\text { Spearman } \\
\text { correlation }\left(r_{s}\right)\end{array}$} & \multirow[b]{2}{*}{$p$-Value ${ }^{a}$} \\
\hline & & Total enterococci & E. faecalis & E. faecium & E. durans & E. hirae & $\begin{array}{l}\text { Other Enterococcus } \\
\text { spp. }\end{array}$ & & \\
\hline 1 & gelE $^{+}$ & $30(35.7 I)$ & $17(20.24)$ & $8(9.52)$ & $3(3.57)$ & $\mathrm{I}(\mathrm{I} .19)$ & $\mathrm{I}(\mathrm{I} .19)$ & I & $0.0083^{* *}$ \\
\hline 2 & $e s p^{+}$ & $4(4.76)$ & 0 & $2(2.38)$ & $\mathrm{I}(1.19)$ & $I(1.19)$ & 0 & 1 & $0.0083^{* *}$ \\
\hline 3 & $\mathrm{efaA} A^{+}$ & $4(4.76)$ & $\mathrm{I}(\mathrm{I.19})$ & $2(2.38)$ & 0 & $I(1.19)$ & 0 & 0.8208 & 0.0667 \\
\hline 4 & $a_{c e}^{+}$ & $2(2.38)$ & $I(I .19)$ & 0 & 0 & $I(1.19)$ & 0 & 0.4472 & 0.225 \\
\hline 5 & gelE $^{+} e^{+} p^{+}$ & $22(26.19)$ & $17(20.24)$ & $2(2.38)$ & $3(3.57)$ & 0 & 0 & 0.9747 & $0.0083^{* *}$ \\
\hline 6 & $\mathrm{gelE}^{+} \mathrm{efa} \mathrm{A}^{+}$ & $6(7.14)$ & $4(4.76)$ & $2(2.38)$ & 0 & 0 & 0 & 0.8944 & $0.0417^{*}$ \\
\hline 7 & $\mathrm{gelE}^{+} a c e^{+} e f a A^{+}$ & $2(2.38)$ & $2(2.38)$ & 0 & 0 & 0 & 0 & 0.7071 & 0.1167 \\
\hline 8 & gelE $E^{+} e f a A^{+} e s p^{+}$ & $15(17.86)$ & $10(11.9)$ & $4(4.76)$ & 0 & $\mathrm{I}(1.19)$ & 0 & 0.8208 & 0.0667 \\
\hline
\end{tabular}

ap-Value was calculated using Wilcoxon matched pair test. **/* p-value summary for significantly effective pairing. 
confluence just upstream of this site. Site 5 is Jajmau, the most downstream site, hub for tanneries and receives municipal waste from whole city.

\section{Sample collection}

A cross-sectional approach was used to collect surface water samples. Samples were collected in triplicate $(\mathrm{n}=$ 15) from five locations situated in up-to-down-gradient fashion (Figure 1). In brief, three transects were established randomly at each site and water samples $(1 \mathrm{~L})$ were collected $30 \mathrm{~cm}$ below water surface from left, mid and right bank of the river along each transect. Surface water samples were stored in sterile glass bottles, labeled and transported on ice to the laboratory for analysis. Sample processing and analysis was conducted within $6 \mathrm{hr}$ after sample collection.

\section{Isolation and enumeration of Enterococci}

Quantitative enumeration of enterococci from selected sites was performed as per APHA [40] using the Multiple Tube Fermentation Technique and reported as MPN index/100 ml surface water. Additionally, enterococci were enumerated from each sample using standard membrane filtration method and reported as CFU/100 ml surface water [41]. Presumptive enterococci recovered ( $\mathrm{n}=$ 30) from each sample were identified by biochemical tests including catalase test and PYR test. The growth of isolates was determined in $6.5 \% \mathrm{NaCl}, \mathrm{pH} 9.6$, and at 10 and $45^{\circ} \mathrm{C}$, respectively. All confirmed enterococci isolates were archived in tryptic soy broth with $15 \%$ glycerol at $80^{\circ} \mathrm{C}$ for further analyses.

\section{Characterization of Enterococcus spp. using Polymerase Chain Reaction}

All isolates confirmed by biochemical tests were subjected to genotypic characterization by Polymerase Chain Reaction (PCR) technique. The presence of $t u f$ gene encoding the elongation factor EF-Tu in genus Enterococcus and the sodA variant for E. faecalis, E. faecium, E. durans and E. hirae species were investigated by PCR as reported earlier $[42,43]$. An isolate not belonging to the four species of enterococci genotypically characterized by PCR in this study was listed as "other Enterococcus spp."

\section{Antimicrobial susceptibility testing}

A panel of thirteen antimicrobials (antimicrobial abbreviation:mcg/disc) impregnated on paper discs (Himedia Ltd., India) belonging to eight different group of antimicrobials as Fluoroquinolone: Norfloxacin (Nx:10 mcg), $\beta$ lactam: Ampicillin (A:10 mcg), Oxacillin (Ox:1 mcg), PenicillinG (P:10 units), Methicillin (M:5 mcg), Aminoglycoside: Gentamicin (G:10 mcg), Streptomycin (S:10 mcg), Tetracycline: Tetracycline (T:30 mcg), Phenicol: Chloramphenicol (C:30 mcg), Macrolide: Erythromycin (E:15 mcg), Rifamycin: Rifampicin (R:5 mcg),
Glycopeptides: Vancomycin (Va:30 mcg), Teicoplanin (Te:30 mcg) were used for testing the sensitivity of isolated organisms by Kirby-Bauer disc diffusion test as described by CLSI $[31,44]$. The diameter of zones showing inhibition were measured to the nearest $\mathrm{mm}$ and recorded. A zone size interpretive chart was used to determine sensitivity/resistance of antimicrobials as described by CLSI [44].

\section{Determination of virulence-markers distribution in enterococci}

Polymerase Chain Reaction technique was used to generate a profile for virulence-markers' distribution in enterococci. The presence of genes gelE, ace, efaA and esp encoding gelatinase, adhesion collagen factor, endocarditis factor antigen and enterococcal surface protein, respectively in different Enterococcus spp. was examined by PCR as reported earlier $[7,45]$. The amplicons were electrophoresed on 2\% agarose gel in Tris-acetate-EDTA buffer supplemented with $0.5 \mu \mathrm{g} / \mathrm{ml}$ of ethidium bromide and calibrated using 50 bp and 100 bp DNA ladders (MBI Fermentas, USA). All enterococci isolates were subjected to phenotypic gelatinase assay as described by Gilmore et al. [2]. E. faecalis ATCC 51229, E. faecium ATCC 35667, 27270, E. durans ATCC 49470, E. hirae ATCC 9790 were used throughout the study as reference/standard strains.

\section{Statistical analyses}

We compared concentrations of enterococci obtained using MPN analysis test and membrane filtration method from up-to-down-gradient surface water samples. Chisquare test for trend was applied for the purpose. The distribution of Enterococcus spp. and its association with the landscape was evaluated using Chi-square test. The prevalence and distribution of antimicrobial-resistance and virulence-markers among isolates from up-to-down-gradient landscape was assessed using Wilcoxon rank-sum tests. Wilcoxon matched pair test was conducted to investigate correlation between dissemination of antimicrobialresistance and virulence-markers in different Enterococcus spp. All statistical analyses were performed using GraphPad Prism version 5.0 for Windows (GraphPad Software, San Diego, California, USA, http://www.graphpad.com).

\section{Authors' contributions}

PL carried out the phenotypic antimicrobial susceptibility profiling, determination of gelatinase activity, PCR characterization for determination of enterococcal species diversity and virulence marker's distribution, analysed the data and wrote the manuscript. SR contributed to sample collection and microbiological analysis. MA provided direction on available means of data analyses. RS conceived the study, analysed the data and wrote the manuscript. All authors contributed to the general content and structure of the final manuscript. 


\section{Additional material}

\section{Additional file 1}

Table A1-Correlation observed between the prevalence of single/multiple-antimicrobial-resistance and Enterococcus species diversity in the landscape. Presentation of correlation between the single or multipleantimicrobial-resistance and different Enterococcus species recovered from the landscape.

Click here for file

[http://www.biomedcentral.com/content/supplementary/14712180-9-140-S1.doc]

\section{Additional file 2}

Table A2- Site wise elaborated profile of species diversity, antimicrobial-resistance and virulence-markers in enterococci isolates from river Ganga at Kanpur city. Depiction of investigated enterococcal species diversity, antimicrobial-resistance and virulence-markers' profile of all isolates recovered from the landscape.

Click here for file

[http://www.biomedcentral.com/content/supplementary/14712180-9-140-S2.doc]

\section{Acknowledgements}

This work was supported by CSIR Network Project SMM-05. The financial assistance to PL (SRF) and SR (SRF) from CSIR, Government of India is acknowledged. IITR manuscript \# 27I2.

\section{References}

I. Murray BE, Weinstock GM: Enterococci: new aspects of an old organism. Proc Assoc Am Physicians 1999, I I I:328-334.

2. Gilmore MS, Coburn PS, Nallapareddy SR, Murray BE: Enterococcal virulence. In The Enterococci: Pathogenesis, Molecular biology and Antibiotic Resistance Edited by: Gilmore MS, Clewell DB, Courvalin P, Dunny GM, Murray BE, Rice LB. Washington DC: American Society for Microbiology Press; 2002:317.

3. U.S. EPA: Bacterial Water Quality Standards for Recreational Waters (Freshwater and Marine Waters). EPA-823-R-03-008 2003 [http://www.epa.gov/waterscience/beaches/local/statrept.pdf]. Washington, DC:U.S. Environmental Protection Agency

4. Cabelli V, Dufour AP, McCabe LJ, Levin MA: Swimming-associated gastroenteritis and water quality. Am J Epidemiol 1982, I 15:606-616.

5. Coque TM, Patterson JE, Steckelberg JM, Murray BE: Incidence of hemolysin, gelatinase, and aggregation substance among enterococci isolated from patients with endocarditis and other infections and from feces of hospitalized and community-based persons. J Infect Dis 1995, I 7 I: I 223-1229.

6. Lowe AM, Lambert PA, Smith AW: Cloning of an Enterococcus faecalis endocarditis antigen: homology with adhesins from some oral streptococci. Infect Immun 1995, 63:703-706.

7. Eaton TJ, Gasson MJ: Molecular screening of enterococcus virulence determinants and potential for genetic exchange between food and medical isolates. Appl Environ Microbiol 200I, 67:1628-1635.

8. Huycke MM, Sahm DF, Gilmore MS: Multiple-drug resistant enterococci: The nature of the problem and an agenda for the future. Emerg Infect Dis 1998, 4:239-249.

9. Moellering RC Jr: Emergence of enterococcus as a significant pathogen. Clin Infect Dis 1992, I4:1 173-II 78.

10. Mundy LM, Sahm DF, Gilmore M: Relationship between enterococcal virulence and antimicrobial resistance. Clin Microbiol Rev 2000, 13:513-522.

II. Taneja N, Rani P, Emmanuel R, Sharma M: Significance of vancomycin resistant enterococci from urinary specimens at a tertiary care centre in northern India. Indian J Med Res 2004, I 1 9:72-74.
12. Ghoshal U, Garg A, Tiwari DP, Ayyagiri A: Emerging vancomycin resistance in enterococci in India. Indian J Pathol Microbiol 2006, 49:620-622.

13. Agrawal J, Kalyan R, Singh M: High-level aminoglycoside resistance and Beta-lactamase production in enterococci at a tertiary care hospital in India. Jpn J Infect Dis 2009, 62:158-159.

14. Moore DF, Guzman JA, McGee C: Species distribution and antimicrobial resistance of enterococci isolated from surface and ocean water. J Appl Microbiol 2008, 105:1017-1025.

15. Novais C, Coque TM, Ferreira H, Sousa JC, Peixe L: Environmental Contamination with Vancomycin-Resistant Enterococci from Hospital Sewage in Portugal. Appl Environ Microbiol 2005, 71:3364-3368.

16. Ahmed W, Neller R, Katouli M: Host species-specific metabolic fingerprint database for Enterococci and Escherichia coli and its application to identify sources of fecal contamination in surface waters. Appl Environ Microbiol 2005, 71:446I-4468.

17. Randall SS, Ward MP, Maldonado G: Can landscape ecology untangle the complexity of antibiotic resistance. Nat Rev Microbiol. 2006, 4(I 2):943-952.

18. Ram S, Vajpayee P, Shanker R: Prevalence of multi-antimicrobial-agent resistant, shiga toxin and enterotoxin producing Escherichia coli in surface waters of river Ganga. Environ $\mathrm{Sci}$ Technol. 2007, 4 I (21):7383-7388.

19. Central Pollution Control Board (CPCB): Annual Report: Air and water quality monitoring network 2002 [http://cpcbenvis.nic.in/ar2003/ar23ch5.htm].

20. Central Pollution Control Board (CPCB): National Water Quality Monitoring at a Glance 2005 [http://cpcbenvis.nic.in/wq-2005/ watmain2005.htm].

21. Hamelin K, Bruant G, Shaarawi AE, Stephen H, Thomas AE, Fairbrother J: Occurrence of virulence and antimicrobial resistance genes in Escherichia coli isolates from different aquatic ecosystems within the St. Clair river and Detroit river areas. Appl Environ Microbiol 2007, 73:477-484.

22. Sapkota AR, Curriero FC, Gibson KE, Schwab KJ: Antibiotic-resistant enterococci and fecal indicators in surface water and groundwater impacted by a concentrated swine feeding operation. Environ Health Perspect 2007, I I 5: 1040- 1045.

23. Rawlings TK: Interactions of Vibrio cholerae serogroups $O I$ and 0139 and copepods. In PhD Thesis University of Maryland, Faculty of the Graduate School, College Park; 2005.

24. Gordon S, Swenson JM, Hill BC, Pigott NE, Facklam RR, Cooksey RC, Thornsberry C, Jarvis WR, Tenover FC: Antimicrobial susceptibility patterns of common and unusual species of enterococci causing infections in the United States. J Clin Microbiol 1992, 30:2373-2378.

25. Aarestrup FM, Kruse H, Tast E, Hammerum AM, Jensen LB: Associations between the use of antimicrobial agents for growth promotion and the occurrence of resistance among $E$. faecium from broilers and pigs in Denmark, Finland, and Norway. Microb Drug Resist 2000, 6:63-70.

26. Thurston-Enriquez JA, Gilley JE, Eghball B: Microbial quality of runoff following land application of cattle manure and swine slurry. J Water Health 2005, 3:I57-I7I.

27. Hasman H, Aarestrup FM: Relationship between copper, glycopeptide, and macrolide resistance among Enterococcus faecium strains isolated from pigs in Denmark between 1997 and 2003. Antimicrob Agents Chemother 2005, 49:454-456.

28. Sletvold H, Johnsen PJ, Simonsen GS, Aasnæs B, Sundsfjord A, Nielsen $\mathrm{KM}$ : Comparative DNA analysis of two vanA plasmids from enterococcus faecium strains isolated from poultry and a poultry farmer in norway. Antimicrob Agents Chemoth 2007, 51:736-739.

29. Garcia-Migura L, Hasman H, Svendsen C, Jensen LB: Relevance of hot spots in the evolution and transmission of TnI546 in glycopeptide-resistant Enterococcus faecium (GREF) from broiler origin. J Antimicrob Chemother 2008, 62:68I-687.

30. Cetinkaya $Y$, Falk P, Mayhall CG: Vancomycin-resistant enterococci. Clin Microbiol Rev 2000, I 3:686-707.

31. Lata P, Ram S, Agrawal M, Shanker R: Real Time PCR for the Rapid Detection of vanA Gene in Surface Waters and Aquatic Macrophyte by Molecular Beacon Probe. Environ Sci Technol 2009, 43:3343-3348.

32. Jett BD, Huycke MM, Gilmore MS: Virulence of enterococci. Clin Microbiol Rev 1994, 7:462-478. 
33. Coque TM, Willems R, Canton R, Del Campo R, Baquero F: High occurrence of esp among ampicillin-resistant and vancomycin-susceptible Enterococcus faecium clones from hospitalized patients. J Antimicrob Chemother 2002, 50:1035-1038.

34. Semedo T, Santos MA, Lopes MF, Figueiredo Marques J], Barreto Crespo MT, Tenreiro R: Virulence factors in food, clinical and reference enterococci: a common trait in the genus. Syst Appl Microbiol 2003, 26: I 3-22.

35. Macovei L, Ghosh A, Thomas VC, Hancock LE, Mahmood S, Zurek L: Enterococcus faecalis with the gelatinase phenotype regulated by the fsr operon and with biofilm-forming capacity are common in the agricultural environment. Environ Microbio 2009, II:I540-1547.

36. Dunny GM, Clewell DB: Transmissible toxin (hemolysin) plasmid in Streptococcus faecalis and its mobilization of a noninfectious drug resistance plasmid. J Bacteriol 1975, I 24:784-790.

37. Heaton MP, Discotto LF, Pucci MJ, Handwerger S: Mobilization of vancomycin resistance by transposon-mediated fusion of a VanA plasmid with an Enterococcus faecium sex pheromoneresponse plasmid. Gene 1996, 171:9-17.

38. Moritz EM, Hergenrother PJ: Toxin-antitoxin systems are ubiquitous and plasmid-encoded in vancomycin-resistant enterococci. Proc Natl Acad Sci 2007, 104:3 I I-316.

39. Pandey DP, Gerdes K: Toxin-antitoxin loci are highly abundant in free-living but lost from host-associated prokaryotes. Nucleic Acids Res 2005, 33:966-976.

40. APHA: Standard Methods for the Examination of Water and Wastewater. 20th edition. Washington, DC: American Public Health Association; 1998.

4I. U.S. EPA: Improved Enumeration Methods for the Recreational Water Quality Indicators: Enterococci and Escherichia coli. EPA/82I/R-97/004 2000 [http://www.epa.gov/ microbes/RecManv.pdf]. Washington, DC:U.S. Environmental Protection Agency

42. Ke D, Picard FOJ, Martineau F, Nard CM, Roy PH, Ouellette M, Bergeron MG: Development of a PCR assay for rapid detection of Enterococci. J Clin Microbiol I999, 37:3497-3503.

43. Jackson CR, Fedorka-Cray PJ, Barrett JB: Use of a genus and species-specific multiplex PCR for identification of enterococci. J Clin Microbiol 2004, 42:3558-3565.

44. CLSI (Clinical and Laboratory Standards Institute): Performance Standards for Antimicrobial Disk and Dilution Susceptibility Tests for Bacteria Isolated from Animals; Approved Standard-Second edition Wayne, PA:National Committee for Clinical Laboratory Standards; 2002.

45. Creti R, Imperi M, Bertuccini L, Fabretti F, Orefici G, Rosa RD, Baldassarri $L:$ Survey for virulence determinants among Enterococcus faecalis isolated from different sources. J Med Microbiol 2004, 53:13-20.

Publish with Biomed Central and every scientist can read your work free of charge

"BioMed Central will be the most significant development for disseminating the results of biomedical research in our lifetime. "

Sir Paul Nurse, Cancer Research UK

Your research papers will be:

- available free of charge to the entire biomedical community

- peer reviewed and published immediately upon acceptance

- cited in PubMed and archived on PubMed Central

- yours - you keep the copyright
BioMedcentral 